\title{
MECHANICAL PERFORMANCE OF WELDED HOLLOW SPHERICAL JOINTS AT ELEVATED TEMPERATURES
}

\author{
Hong-bo Liu ${ }^{1,3,4}$, Ying-jie Zhang ${ }^{3}$, Lan Wang ${ }^{2}$, Zhi-hua Chen ${ }^{1,3,4}$ \\ ${ }^{1}$ State Key Laboratory of Hydraulic Engineering Simulation and Safety, Tianjin University, Tianjin 300072, China \\ ${ }^{2}$ Tianjin Fire Research Institute of MEM, Tianjin 300000, China \\ ${ }^{3}$ Department of Civil Engineering, Tianjin University, Tianjin 300072, China \\ ${ }^{4}$ Key Laboratory of Coast Civil Structure and Safety, Ministry of Education (Tianjin University), Tianjin 300072, China \\ *(Corresponding author: E-mail: hbliu@tju.edu.cn)
}

\section{A B S T R A C T}

Welded hollow spherical joints (WHSJs) have been extensively applied to spatial grid structures. However, the failure mechanism and assessment method of WHSJs under fire conditions have been rarely studied. In this study, the failure mechanism and high-temperature attenuation pattern of the axial compression performance of WHSJs at fire-induced high temperatures were explored via high-temperature axial compression experiments by using 18 specimens. A finite element (FE) model was constructed by using the ABAQUS software. The reliability of this FE model was verified by experimental results. The influencing patterns of the type of steel, stiffening rib arrangement, size of the WHSJ, and the test temperature on the high-temperature axial compression performance of WHSJs were discussed through the FE model. A simplified calculation method of the compressive bearing capacity of WHSJs at elevated temperatures was proposed on the basis of the test data and the FE parameterized analysis results. The findings of the simplified calculation method conformed to experimental and numerical simulation results.
ART I CLE H I S T O RY

$\begin{array}{ll}\text { Received: } & \text { 11 March } 2019 \\ \text { Revised: } & \text { 11 August } 2019 \\ \text { Accepted: } & \text { 14 September } 2019\end{array}$

\section{K E Y W O R D S}

Welded hollow spherical joint; Under fire;

Axial compression experiment;

Compressive bearing capacity;

Initial axial stiffness;

High-temperature attenuation mechanism

\section{Introduction}

Joints in the spatial grid structure mainly include WHSJs, bolted hollow spherical joints, hub-type joints, cast steel joints, tubular joints, and Temcor joints (Fig. 1) [1,2,3,4,5]. WHSJs were proposed by Professor Liu [6] from Tianjin University in 1965 . With a clear load path and convenient connection with other components, WHSJs have become one of the joint forms used mostly in China.

Fire hazards constitute the main disaster that causes architectural structural damages. At elevated temperatures attributed to a fire disaster, the mechanical properties of steel materials change remarkably. The yield strength of steel materials at $400{ }^{\circ} \mathrm{C}$ decreases to $50 \%$ of that at room temperature, and steel materials lose their bearing capacity at temperatures higher than $600{ }^{\circ} \mathrm{C}$ [7]. The failure of WHSJs during fire disasters may cause the collapse of overall structures. Therefore, the study of the mechanical properties of WHSJs at elevated temperatures plays an important role in examining the overall performance of spatial grid structures that use these joints during fire disasters.

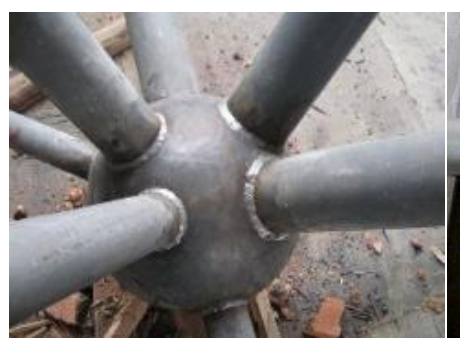

(a) Welded hollow spherical joint

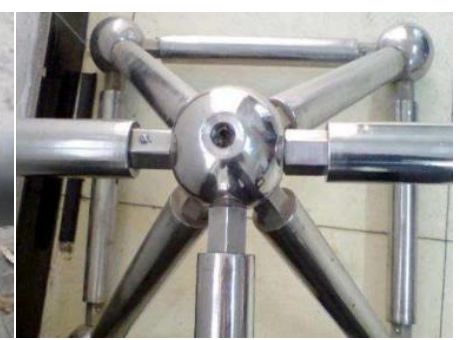

(b) Bolted hollow spherical joint
Fig. 1 Typical joint forms used in the spatial grid structure.

Studies on WHSJs have mainly focused on the mechanical properties of WHSJs at room temperature, and a relatively ideal analysis and design method has been established. Xue [8] studied the failure mechanism of WHSJs with round steel tubes under compressive load and proposed a practical calculation method of its bearing capacity. Ding et al. [9] constructed the tensile and compressive mechanical calculation models of WHSJs with circular steel tubes. Han [10] performed tests and numerical simulations and developed a calculation formula of the tensile and compressive bearing capacity of WHSJs with round steel tubes through regression analysis. The diameter limit is extended to $900 \mathrm{~mm}$. $\mathrm{Li}$ [11] examined the influences of axial force, bending moment, and their combination on the bearing capacity of WHSJs with round steel tubes and proposed a relevant formula. Liu et al. [12] suggested calculation formulas for the tensile and compressive bearing capacity of WHSJs with H-shaped steel tubes through experimental studies and numerical simulation. Han and Liu [13] introduced a theory and practical formula of the initial rigidity of WHSJs and analyzed the influences of joint rigidity on the overall reticulated shell. Zhao [14] examined the effects of WHSJs on the mechanical properties of a single-layered reticulated structure through numerical simulation and found that such effects are related to structure size. Zhao and Wang et al. $[15,16]$ analyzed the influences of welded residual stress on the mechanical properties of WHSJs through numerical simulation. Zhao $[17,18]$ discussed the effects of corrosion at different places on the bending rigidity of WHSJs through a series of nonlinear numerical analyses. The probabilistic distribution model of corroded WHSJs with random pit corrosion has also been proposed. Furthermore, the design methods of WHSJs is introduced to the Technical Regulation of the Space Grid Structure (JGJ7-2010) [19].

The performance of WHSJs at elevated temperatures has been rarely investigated. Liu and Lu et al. [20,21,22] experimentally studied the post-fire residual load-bearing capacity and initial axial stiffness of WHSJs. The design methods of predicting the post-fire residual bearing capacity of WHSJs under axial compression or eccentric compression have also been proposed. Xue [23] performed a high-temperature axial compression experimental study on WHSJs and obtained the temperature field distribution and load-displacement relation curve of these joints.

The bearing capacity of WHSJs at elevated temperatures has yet to be quantitatively analyzed. The rigidity of WHSJs at elevated temperatures has been rarely explored. In this study, the mechanical behaviors of WHSJs at elevated temperatures, such as initial axial stiffness, yield loads, and load-bearing capacities, were examined through tests and numerical simulation. A simplified calculation formula of the bearing capacity of the WHSJs at elevated temperatures was proposed on the basis of numerical analysis results.

\section{Experimental investigation}

\subsection{Test specimen design}

In consideration of various parameters, including type of steel, stiffening 


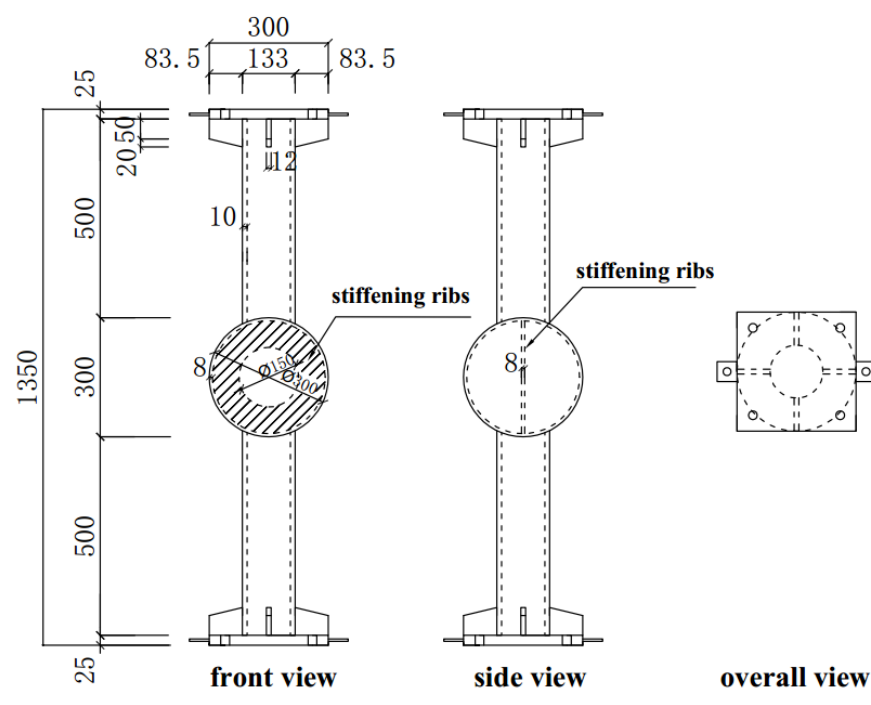

(a) WHSJ specimen without stiffening ribs

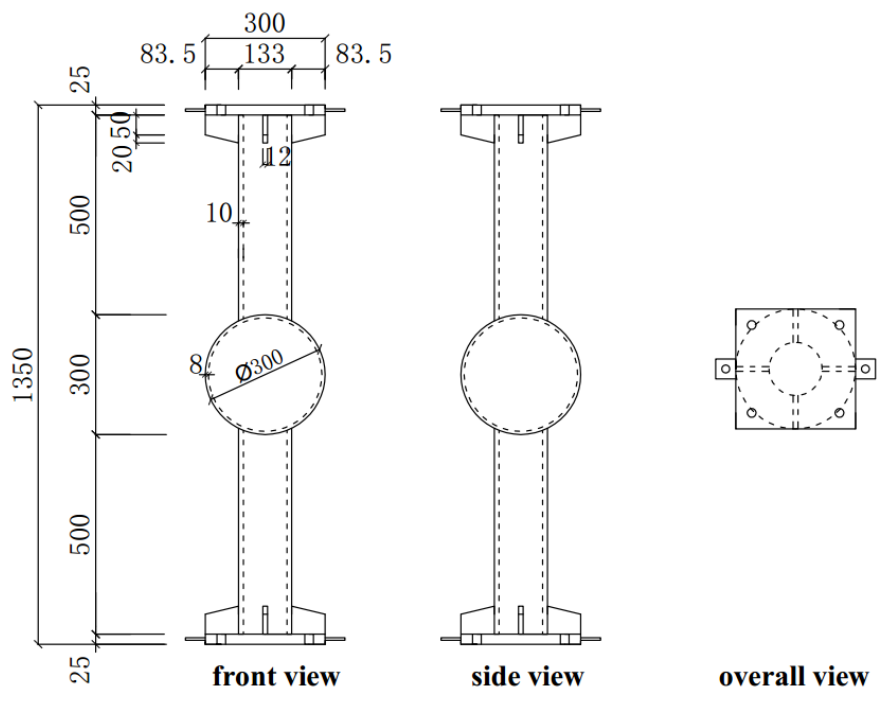

(b) WHSJ specimen with stiffening ribs

Fig. 2 Dimension of the specimens (unit: $\mathrm{mm}$ )

Table 1

Specimen parameters

\begin{tabular}{|c|c|c|c|c|c|c|c|}
\hline Group No. & Joint No. & $D / \mathrm{mm}$ & $t / \mathrm{mm}$ & Steel grade & Stiffening ribs present & $T / P C$ & Quantity \\
\hline 1 & WS-345-20 & 300 & 8 & Q345 & No & 20 & 1 \\
\hline 2 & WS-345-300 & 300 & 8 & Q345 & No & 300 & 3 \\
\hline 3 & WS-345-500 & 300 & 8 & Q345 & No & 500 & 3 \\
\hline 4 & WS-345-700 & 300 & 8 & Q345 & No & 700 & 3 \\
\hline 5 & WSR-345-20 & 300 & 8 & Q345 & Yes & 20 & 1 \\
\hline 6 & WSR-345-500 & 300 & 8 & Q345 & Yes & 500 & 3 \\
\hline 7 & WS-235-20 & 300 & 8 & Q235 & No & 20 & 1 \\
\hline 8 & WS-235-500 & 300 & 8 & Q235 & No & 500 & 3 \\
\hline
\end{tabular}

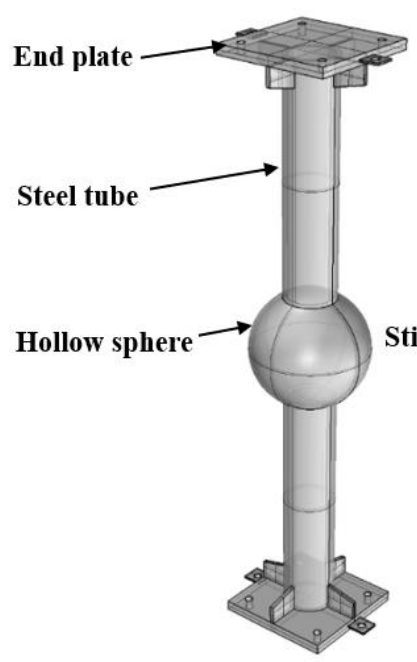

(a) Specimen without stiffening ribs

(b) Specimen with stiffening ribs

Fig. 3 3D visualization of the WHSJ specimens

rib arrangement, and test temperature, 18 WHSJ specimens were designed and prepared. All of the specimens were composed of hollow spheres, steel tubes, and end plates (Fig. 2 and Fig. 3). The outer diameter (D) and the wall thickness (t) of the hollow sphere were 300 and $8 \mathrm{~mm}$, respectively. The outerdiameter $(d)$, the wall thickness $\left(t_{s}\right)$, and the length $(L)$ of the steel tube were 133,10 , and $500 \mathrm{~mm}$, respectively. The end plate size was $300 \mathrm{~mm} \times 300 \mathrm{~mm} \times 25 \mathrm{~mm}$.
Specimens were named according to a certain principle.

For example, in WS-345-300-1 or WSR-345-300-1, WS and WSR denote the joint specimen without stiffening ribs and with stiffening ribs, respectively; 345 represents the steel grade of the specimens (Q345); 300 reflects the test temperature $\left(300^{\circ} \mathrm{C}\right)$; and 1 indicates the number of parallel specimens, which correspond to the first parallel specimen. The detailed information of the specimens is shown in Table 1. The same batch of the steel materials was chosen to test the material properties. The results are presented in Table 2.

Table 2

Material properties

\begin{tabular}{ccccc}
\hline Specimen No. & E/GPa & $f_{y} / \mathrm{MPa}$ & $f_{u} / \mathrm{MPa}$ & $\delta$ \\
\hline Q235-1 & 204.9 & 298.12 & 457.19 & $41.1 \%$ \\
Q235-2 & 205.7 & 302.45 & 449.76 & $37.3 \%$ \\
Q235-3 & 204.2 & 291.69 & 445.15 & $38.2 \%$ \\
Average & 204.9 & 297.42 & 450.70 & $38.9 \%$ \\
Q345-1 & 206.4 & 390.15 & 605.14 & $35.2 \%$ \\
Q345-2 & 204.7 & 386.70 & 600.45 & $34.3 \%$ \\
Q345-3 & 205.6 & 388.86 & 599.12 & $34.0 \%$ \\
Average & 205.6 & 388.57 & 601.57 & $34.5 \%$ \\
\hline
\end{tabular}

\subsection{Experimental scheme}

The experiment involved two steps. First, the specimens were heated from 
room temperature to high temperatures. Second, the high temperature was kept, and the axial compression load was applied. The specimens were heated in a temperature-controlled furnace (Fig. 4). Two thermocouples were placed in a furnace cavity to test air temperature in the furnace. The joint surface was bonded to three thermocouples to test the temperatures of the joint at different positions. The furnace temperature during the heating process was initially raised to $80 \%$ of the target temperature at a rate of $10{ }^{\circ} \mathrm{C} / \mathrm{min}$ and then maintained for $10 \mathrm{~min}$. Subsequently, the furnace temperature was raised to the target temperature at a rate of $5{ }^{\circ} \mathrm{C} / \mathrm{min}$ and then maintained for $30 \mathrm{~min}$. This heating process was adopted to ensure the uniform temperature distribution of the specimens (Fig. 5). In the experiment, air temperature was basically consistent with the joint surface temperature. Axial compressive load was applied to the heated specimens by using a $1200 \mathrm{kN}$ testing machine (Fig. 6). First, preloading was performed. The load was controlled at $10 \%$ of the expected load-bearing capacity and lower than $50 \mathrm{kN}$. Then, formal loading was performed at a displacement rate of $2 \mathrm{~mm} / \mathrm{min}$. The load-displacement curves of the specimens were automatically recorded by the software

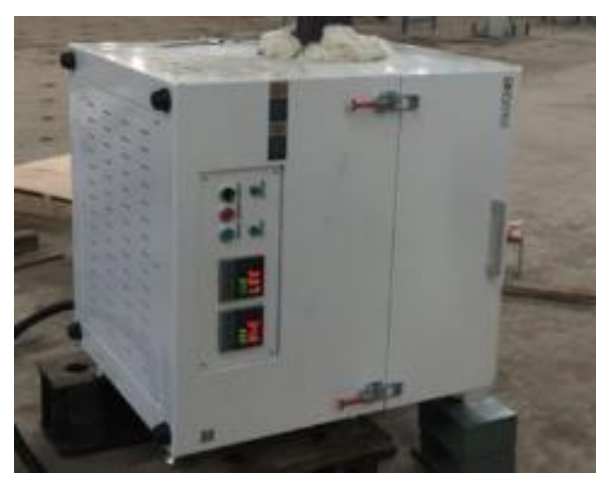

Fig. 4 Temperature-controlled furnace

\subsection{Test results and discussion}

\subsubsection{Failure modes}

The failure modes of the specimens were similar. All of the specimens developed bending invagination at the connection between the spherical joint and the steel tube (Fig. 7). The failure mode can be characterized as an elastoplastic buckling collapse proposed by Han et al. [10]. Moreover, two steel tubes of some specimens were not on the same straight line after the WHSJs failed (Fig. 8). At a high temperature, the steel tubes were protected by asbestos, but the spherical joint had no protection from thermal insulation materials. Furthermore, air temperature in the furnace was not completely uniform, and the properties of the steel materials changed with temperature. The specimens had initial defects. Therefore, different uncertain factors might cause interferences to the specimens.

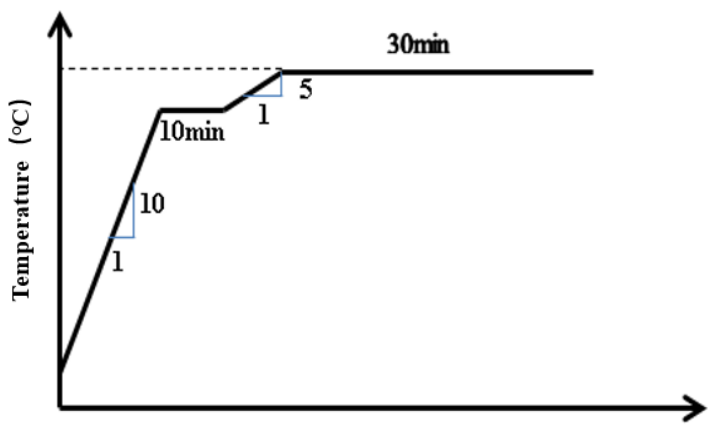

Time (min)

Fig. 5 Heating process

The test phenomena of the specimens differed at various temperatures. The rust on the spherical joint fell off slightly at $\mathrm{T}=300{ }^{\circ} \mathrm{C}$, whereas the weld bead at the connection between the steel tube and the joint turned slightly blue. Some rust on the spherical joint fell off at $\mathrm{T}=500{ }^{\circ} \mathrm{C}$. The joint was dark red, and the weld bead at the connection between the steel tube and the joint became light blue. At $\mathrm{T}=700{ }^{\circ} \mathrm{C}$, the rust on the spherical joint largely fell off. The spherical joint appeared bright red, and the weld bead at the connection between the steel tube and the joint became deep blue (Fig. 9).

\subsubsection{Initial axial rigidity}

The load-displacement curves of all of the specimens are shown in Fig. 10 The curves of some specimens (e.g., WS-345-20 and WSR-345-500-1) were slightly gentle at the initial stage, and the displacement value was between 0 and $1.5 \mathrm{~mm}$, which might be caused by the processing error of these specimens. This stage was the compaction stage of the end plate, which did not influence the test results. At high temperatures $\left(300{ }^{\circ} \mathrm{C}\right.$ and $500{ }^{\circ} \mathrm{C}$ ) and when the value of the load reaches about $130 \mathrm{kN}$, a small stable section of the load-displacement curves formed, which was observed in other tests by using this testing machine. The causes of this phenomenon should be the system setting of the test device connected to the testing machine. The load-displacement curves of each group of parallel specimens except WS-345-300 were close. This finding confirmed the high reliability of the load-displacement curves of the specimens.

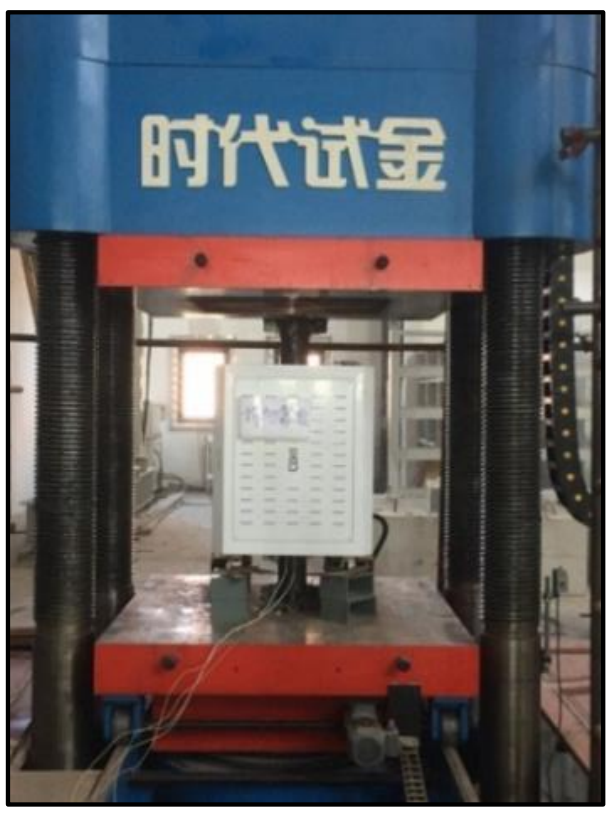

(a) photo of setup

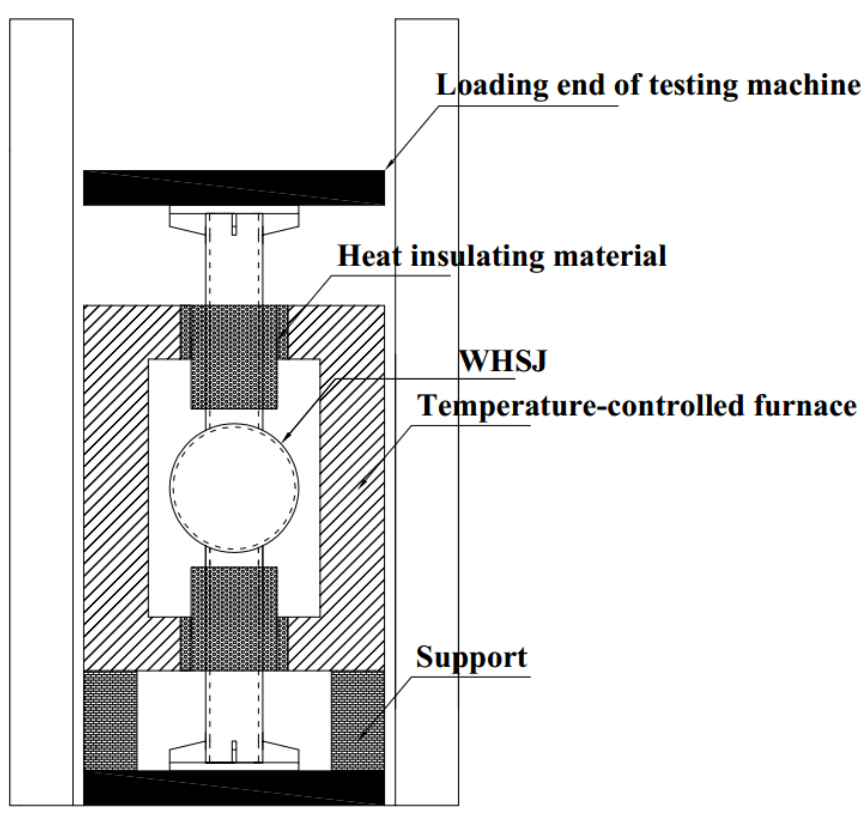

(b) sketch of setup 


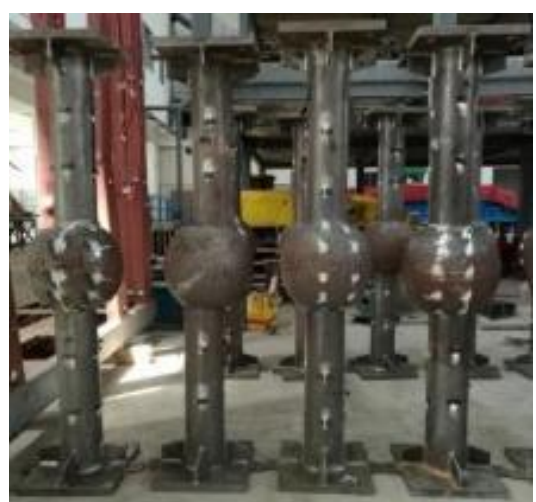

(a)WS-345-20 and WS-345-300 -1 3

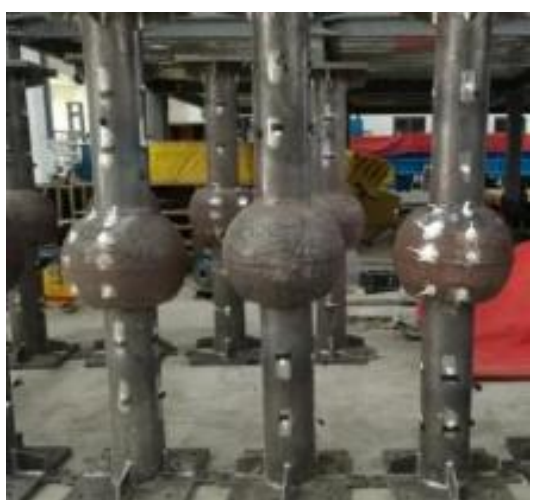

(b)WS-345-500-1 3

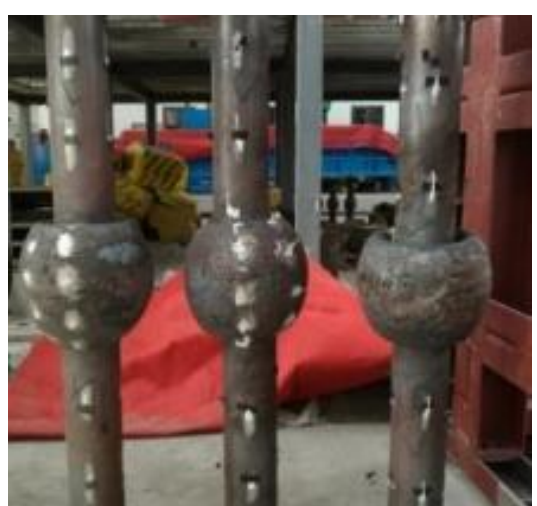

(c)WS-345-700-1 3

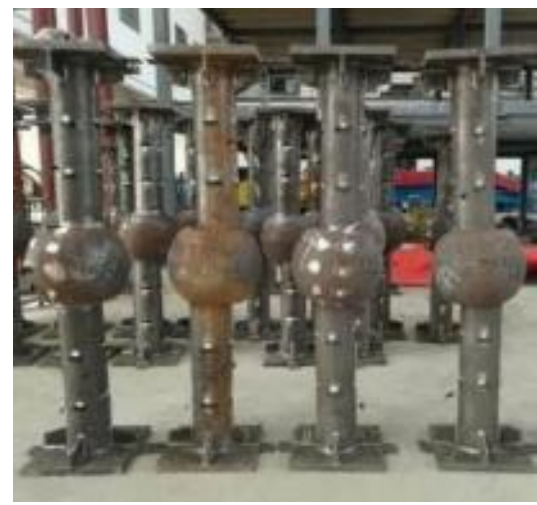

(d) WSR-345-200 and WSR-345-500 -1 3

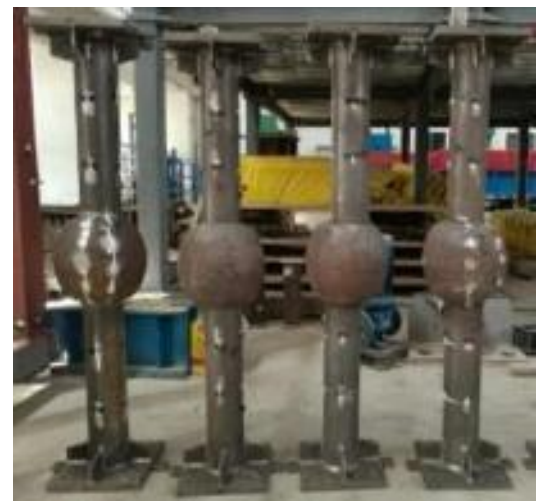

(e) WS-235-20 and WS-235-500-1 3

Fig. 7 Failure modes

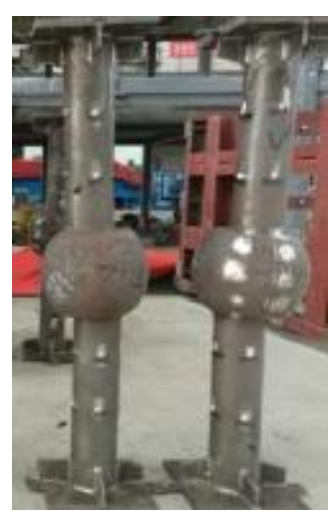

Fig. 8 Misaligned tubes

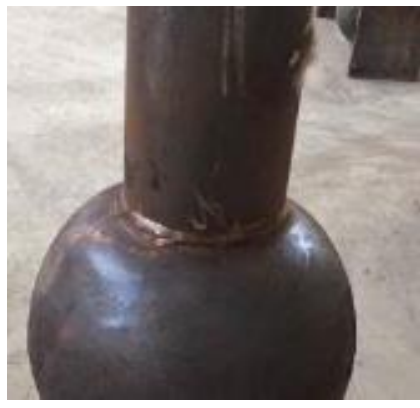

(a) WS-345-300

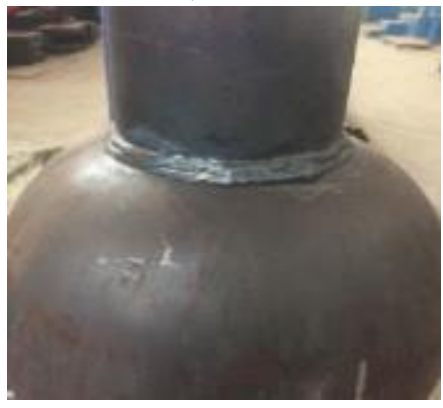

(b) WS-345-500

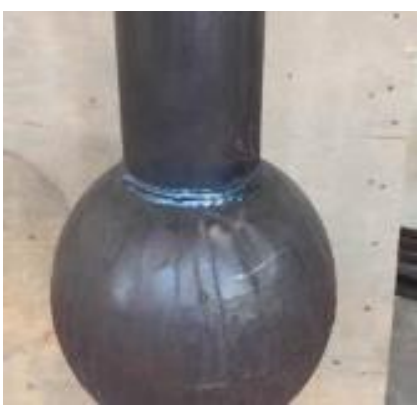

(c)WS-345-700

Fig. 9 Test phenomena of the specimens at different high temperatures 


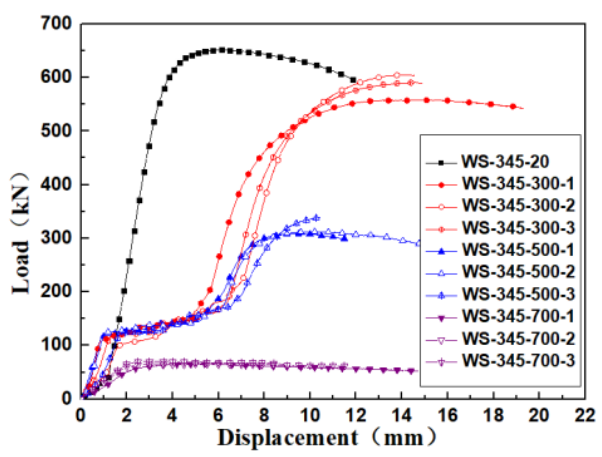

(a) WS-345

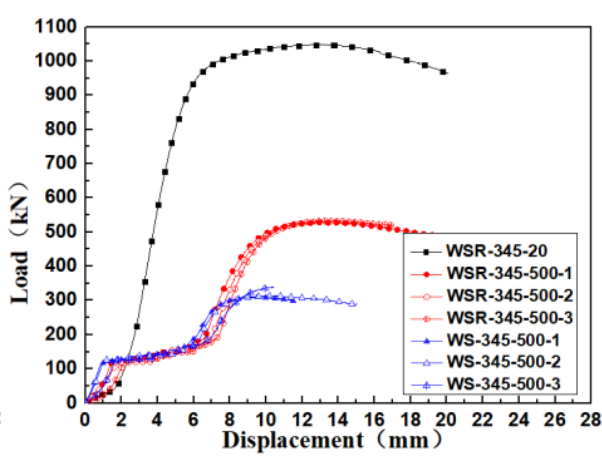

(b) WSR-345

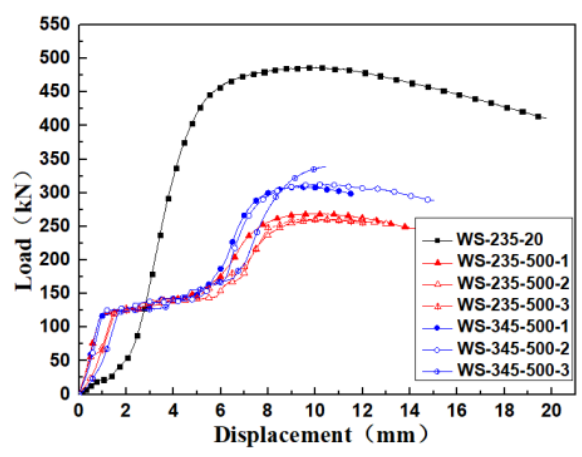

(c) WS-235

Fig. 10 Load-displacement curves of specimens

The failure process of WHSJs under the action of axial load can be divided into three stages [10], as shown in Fig. 11. At the elastic stage, the stiffness of the joint is constant; at the elastoplastic stage and the plastic stage, the load increases slowly as the displacement escalates gradually. The stiffness of the joint degenerates to zero when the ultimate load is reached.

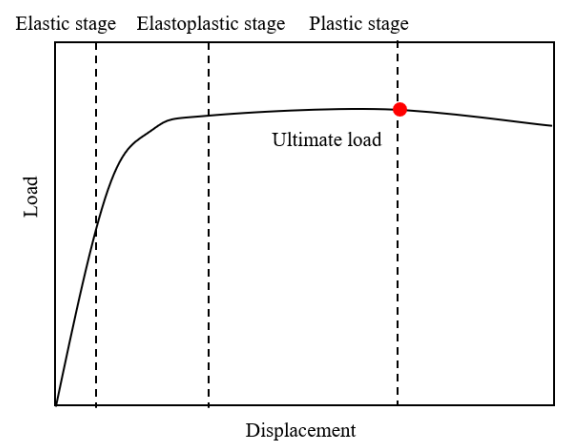

Fig. 11 Load-displacement curve of WHSJs under axial compression

In this study, the initial stiffness at the elastic stage was analyzed and the initial axial rigidity of the WHSJ was defined as follows:

$$
K=N / \Delta
$$

where $K$ is the initial axial rigidity of the WHSJ, $N$ is the axial load at the elastic stage, and $\Delta$ is the vertical displacement of the WHSJ at the elastic stage.

The axial deformation of the upper and lower steel tubes is overlooked because of the limitation of the test conditions. Therefore, $\Delta$ is approximately equal to the displacement of the specimens in this experiment. The reduction coefficient of the initial axial rigidity of the WHSJ at a high temperature $\left(k_{E, T}\right)$ is defined as the ratio between the initial axial rigidity of the WHSJ at a high temperature $\left(K_{T}\right)$ and the initial axial rigidity of the WHSJ at room temperature $\left(K_{20}\right) . K$ and $k_{E, T}$ are listed in Table 3 and plotted in Fig. 12(a) and (b), respectively. The reduction of the initial axial rigidity of the WHSJ is accelerated at temperatures exceeding $500{ }^{\circ} \mathrm{C}$. The axial rigidity of the WHSJ at $300{ }^{\circ} \mathrm{C}$ is approximately $10 \%$ lower than that at room temperature. Such rigidity is about $30 \%$ lower at $500{ }^{\circ} \mathrm{C}$ and approximately $85 \%$ lower at $700{ }^{\circ} \mathrm{C}$ compared with that at room temperature. The stiffening rib arrangement and yield strength of the steel materials slightly influence $k_{E, T}$.

\subsubsection{Yield load and ultimate load}

The determination of the yield load and the ultimate load of the specimens is shown in Fig. 13. The experimentally obtained yield load at high temperatures $\left(N_{\mathrm{yT}}\right)$ and the ultimate load at high temperatures $\left(N_{\mathrm{uT}}\right)$ are shown in Fig. 14(a) and (b), respectively. The reduction coefficient of yield load at high temperatures $\left(\eta_{\mathrm{yT}}\right)$ is defined as the ratio between the yield load at a high temperature $\left(N_{\mathrm{yT}}\right)$ and the yield load at room temperature $\left(N_{\mathrm{y}}\right)$, which is shown in Figure 15 (a). The reduction coefficient of the ultimate load at high temperatures $\left(\eta_{\mathrm{uT}}\right)$ can be defined similarly, which is shown in Fig. 15 (b). The yield load, the ultimate load, and their reduction coefficient are listed in Table 3 . The reduction of the yield load and the ultimate load accelerates significantly at temperatures greater than $300{ }^{\circ} \mathrm{C}$. The yield load and the ultimate load at $300{ }^{\circ} \mathrm{C}$ are approximately
$10 \%$ lower than those at room temperature, and they further decrease to approximately $50 \%$ at $500{ }^{\circ} \mathrm{C}$ and approximately $90 \%$ at $700{ }^{\circ} \mathrm{C}$. The reduction coefficient of the yield load of the same specimens is close to that of the ultimate load. The stiffening rib arrangement and yield strength of steel materials can slightly influence $\eta_{\mathrm{uT}}$ and $\eta_{\mathrm{yT}}$

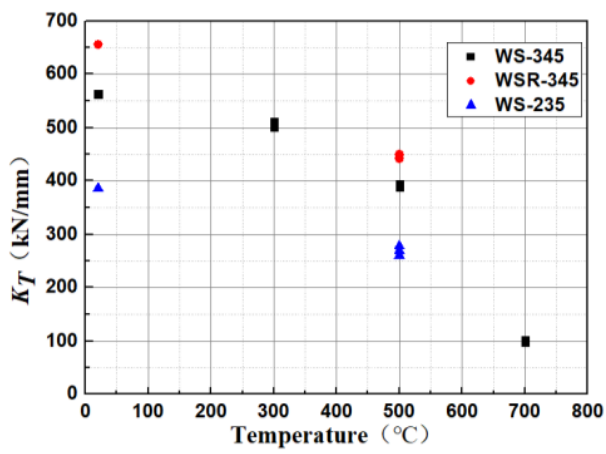

(a) Initial axial rigidity

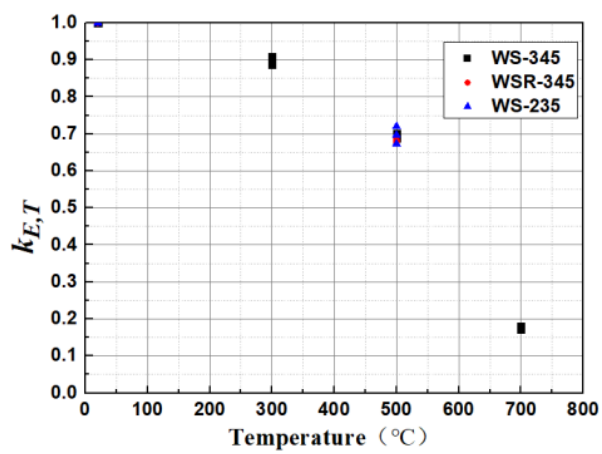

(b) Reduction coefficient of the initial axial rigidity

Fig. 12 Initial axial rigidity and its reduction coefficient

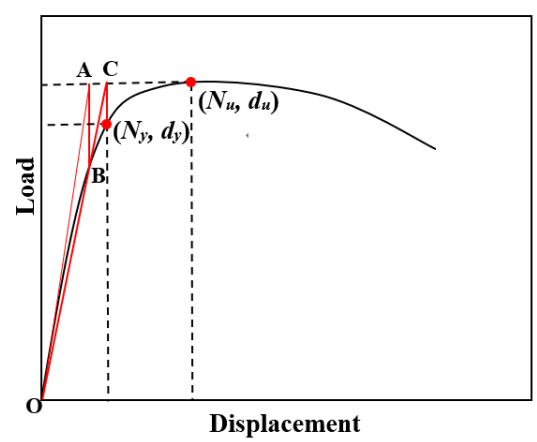

Fig.13 Determination of the yield load and the ultimate load (Note: The line OA is the tangent at the dot.) 


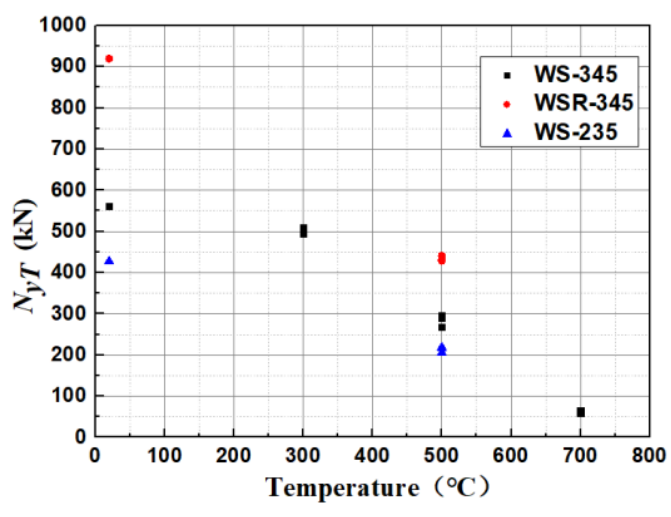

(a) Yield load

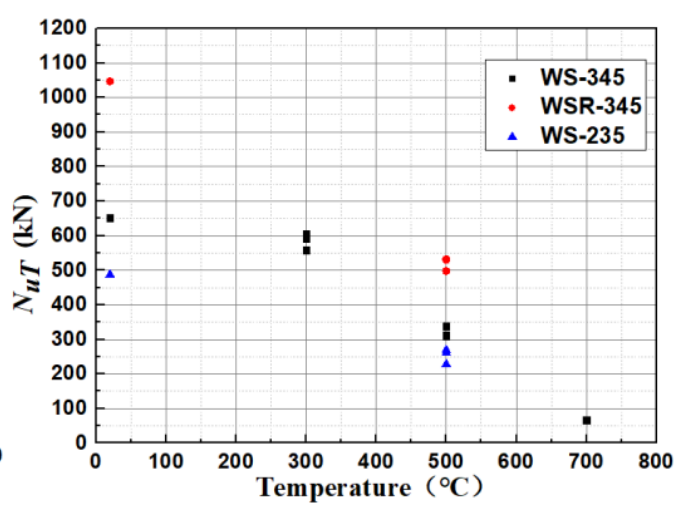

(b) Ultimate load

Fig. 14 Yield load and ultimate load of the specimens

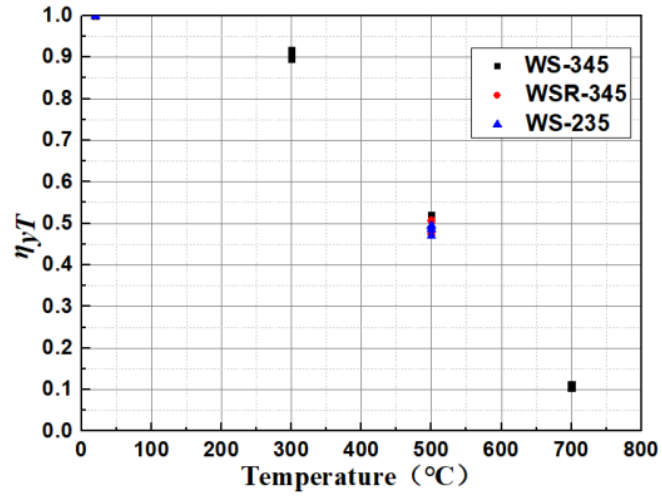

(a) Reduction coefficient of the yield load

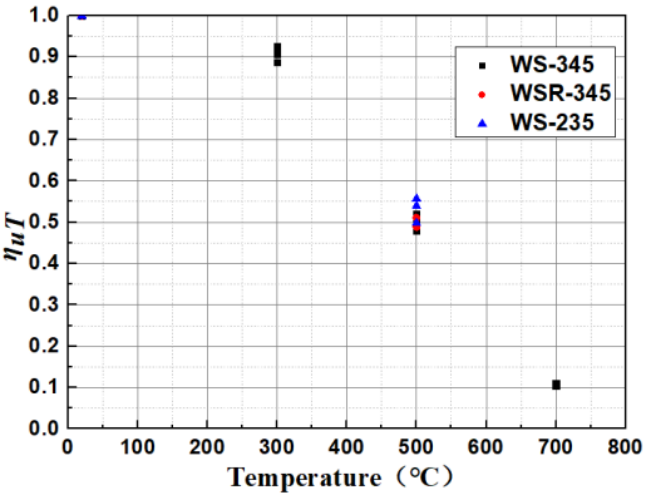

(b) Reduction coefficient of the ultimate load

Fig. 15 Reduction coefficient of the yield load and ultimate load

Table 3

Test results

\begin{tabular}{lllllll}
\hline Joint No. & Rigidity $/ \mathrm{kN} / \mathrm{mm}$ & $k_{\mathrm{E}, T}$ & Yield load $/ \mathrm{kN}$ & $\eta_{y T}$ & Ultimate load $/ \mathrm{kN}$ & $\eta_{u T}$ \\
\hline WS-345-20 & 563 & 1 & 561 & 1 & 652.6 & 1 \\
WS-345-300 & 506 & 0.90 & 507 & 0.90 & 584.9 & 0.90 \\
WS-345-500 & 391 & 0.69 & 277 & 0.49 & 320.4 & 0.49 \\
WS-345-700 & 100 & 0.18 & 60 & 0.11 & 65.4 & 0.10 \\
WS-235-20 & 386 & 1 & 423 & 1 & 486.7 & 1 \\
WS-235-500 & 269 & 0.70 & 213 & 0.50 & 252.7 & 0.52 \\
WSR-345-20 & 656 & 1 & 922 & 1 & 1047.9 & 1 \\
WSR-345-500 & 447 & 0.68 & 429 & 520.2 & 0.50 \\
\hline Note: Data at a high temperature represent the mean value of three specimens in a group.
\end{tabular}

\section{Finite element analysis}

Finite element analysis (FEA) was conducted by using the ABAQUS. The analysis type was static, which considered the nonlinearity of the materials and the geometry.

\subsection{Constitutive model of materials at high temperatures}

The mechanical properties of materials, including elasticity modulus, yield strength, and ultimate strength, may change at high temperatures. Structural analysis accuracy at a high temperature is mainly determined by the stressstrain relation of materials, that is, the determination of different mechanical indices. The smooth curve model (Fig. 16) is defined in EUROCODE3 [24]. In this model, the stress hardening of the steel materials is neglected. The reduction coefficients of the yield strength and the initial elasticity modulus of the steel materials at different temperatures are shown in Table 4. Poisson's ratio of the steel materials at high temperatures is set equal to that at room temperature $(0.3)$ because this ratio is less sensitive to high temperature.

\subsection{Finite element model}

The geometric details of the FE model are consistent with those of the test specimens presented in Section 2.1. The measured thickness of base metal plate of WHSJs is $7.8 \mathrm{~mm}$ (a mean value). Compared to the base metal plate, the thickness of the hollow sphere decreases due to the formation of the oxide film and the stretching of the steel sheet during the process of stamping, and the reduction varies with the locations of the hollow sphere. The reduction coefficient of the thickness of WHSJs $\left(\mu_{\mathrm{t}}\right)$ is defined by Eq. (2):

$\mu_{t}=\frac{t}{t_{0}}$

where $t$ and $t_{0}$ refer to the thickness of WHSJs and the base metal plate, respectively. The value of $\mu_{t}$, which is proposed by Chen [25,26], is between 0.85 and 1 . In the finite element simulation of this paper, the value of $\mu_{t}$ is 0.95 . Therefore, the thickness of the finite element model of WHSJs established in this paper is $7.4 \mathrm{~mm}$.

The 3D eight-node solid element with reduced integration (C3D8R) was used to mesh the model. The stress at the connection between the spherical joint and the steel tubes is relatively high. The meshing density of this region increases. Meshing size can evidently influence the accuracy of the FE model results. Therefore, the sensitivity analysis of the meshing size was performed first. The spherical joint model is meshed by three meshing sizes $(8,467$ elements, 16,776 elements, and 24,112 elements). The corresponding load-displacement curves are shown in Fig. 17. The calculation results of the FE model with 16,776 
elements are close to that of its counterpart with 24,112 elements. This finding suggests that the former meshing size is accurate enough and can meet the accuracy requirements of the FE model. Therefore, the spherical joint model is divided into 16,776 elements (Fig. 18).

In terms of the excellent thermal conductivity of the steel materials, the temperature of the whole specimen can be viewed in uniform distribution. As such, the same material properties and field temperature are applied to the FE model under fire disasters.

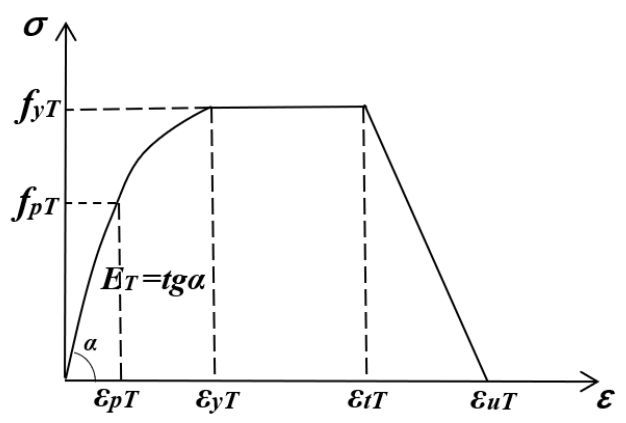

Fig. 16 Constitutive model of materials at high temperatures

\section{Table 4}

Reduction coefficient of the mechanical properties of the steel materials at high temperatures [24]

\begin{tabular}{|c|c|c|}
\hline Temperature $/{ }^{\circ} \mathrm{C}$ & $\begin{array}{c}\text { Reduction coefficient of the } \\
\text { yield strength }\end{array}$ & $\begin{array}{l}\text { Reduction coefficient of the } \\
\text { initial elasticity modulus }\end{array}$ \\
\hline 20 & 1.000 & 1.000 \\
\hline 100 & 1.000 & 1.000 \\
\hline 200 & 1.000 & 0.900 \\
\hline 300 & 1.000 & 0.800 \\
\hline 400 & 1.000 & 0.700 \\
\hline 500 & 0.780 & 0.600 \\
\hline 600 & 0.470 & 0.310 \\
\hline 700 & 0.230 & 0.130 \\
\hline 800 & 0.110 & 0.090 \\
\hline 900 & 0.060 & 0.0675 \\
\hline 1000 & 0.040 & 0.0450 \\
\hline 1100 & 0.020 & 0.0225 \\
\hline 1200 & 0.000 & 0.000 \\
\hline
\end{tabular}

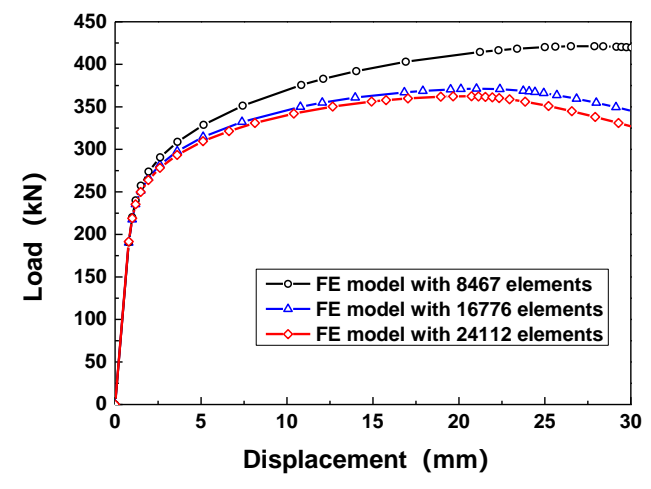

Fig. 17 The influence of meshing sizes

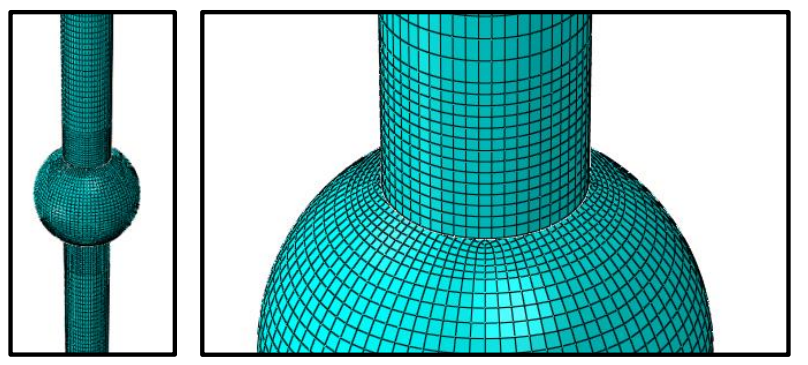

Fig. 18 FE model of the specimen

\subsection{Verification of finite element simulation}

The FEA results are compared with the test results. The typical failure modes and load-displacement curves are shown in Fig. 19 and Fig. 20, respectively. The ultimate bearing capacity and initial axial rigidity of the specimens are presented in Tables 5 and 6, respectively. The failure modes of the spherical joint in the test are consistent with those in FEA. All of the specimens developed bending invagination at the connection between the joint and the steel tubes. The test results agree well with the simulation results in terms of ultimate bearing capacity, initial axial rigidity, and their reduction coefficients. The bearing capacity and rigidity errors of the specimens at $700{ }^{\circ} \mathrm{C}$ are relatively high, reaching $25.2 \%$ and $32 \%$. Other specimens show small error $(<20 \%)$.

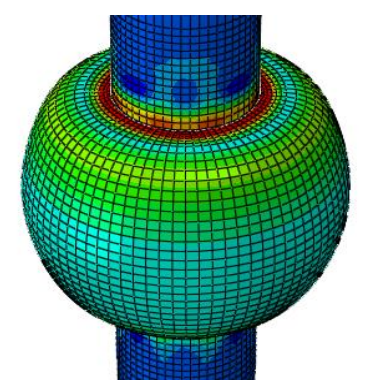

(a) FEA of WS-345-500

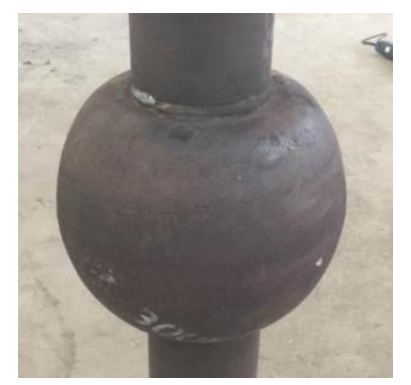

(b) Test results of WS-345-500
Fig. 19 Comparison of typical failure modes between simulation and test results

The differences between the test and FEA in fig. 20 are caused by several reasons. 1) The thickness of the hollow sphere decreases due to the formation of the oxide film and the stretching of the steel sheet during the process of stamping, and the reduction coefficient of thickness of WHSJs $\left(\mu_{\mathrm{t}}\right)$, which is determined by Eq. (2), ranges from 0.85 to 1 according to the recommendations in literatures $[25,26]$. The influence of $\mu_{\mathrm{t}}$ on the bearing capacity is shown in Fig. 21. It indicates that the bearing capacity of WHSJs decreases by $12 \%$ with the $\mu_{\mathrm{t}}$ decreasing by 0.05 .2) The simulated temperature is approximately $50{ }^{\circ} \mathrm{C}$ lower than the test value because the rise of specimen temperature lagged behind the rise of air temperature, resulting in the bearing capacity of WHSJs decreases by about $10 \%$, as shown in Fig. 22. 3) There are residual stress and the loss of material after the process of stamping, which might have detrimental influences on the bearing capacity of the WHSJs. 4) There is discreteness in the quality of the specimen, leading to the values which are inconsistent with the ideal results.

\subsection{Correction of the initial axial rigidity}

Steel tube deformation may remarkably influence the initial rigidity of the WHSJ during fire disasters because the connecting steel tubes are long. The calculation formula of the initial axial rigidity of the WHSJ is shown in Eq. (1), but this formula neglects the influences of the axial deformation of steel tubes. In this section, the accurate calculation formula of the axial deformation of the WHSJ is proposed by considering the axial deformation of steel tubes:

$$
\Delta=\left(\Delta_{2}-\Delta_{3}\right) / 2
$$

where $\Delta_{2}$ is the total displacement of specimens, and $\Delta_{3}$ is the displacement of steel tubes.

The influences of steel tube deformation on the initial axial rigidity of the 
WHSJ at different temperatures are explored through FEA based on WS-345 (Fig. 23). The initial axial rigidity of the joint is significantly smaller when the steel tube deformation is neglected than that when the axial deformation of the steel tubes is considered. Steel tubes develop substantial deformation at high temperatures, and this phenomenon cannot be disregarded in calculating the axial rigidity of the joint. The relation curve between the initial axial rigidity of the WHSJ after the correction and the test temperature is shown in Fig. 24. The axial rigidity of the WHSJ at a high temperature declines gradually and begins to decrease obviously at temperatures higher than $500{ }^{\circ} \mathrm{C}$.

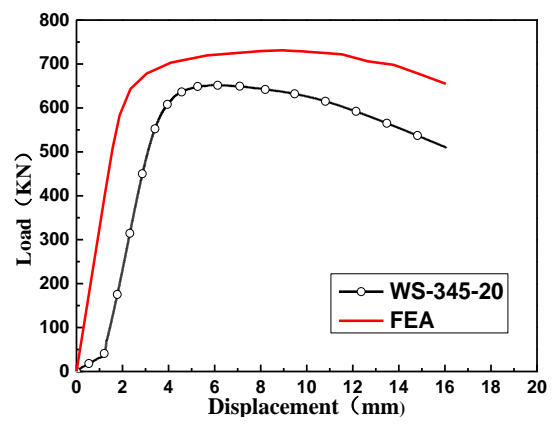

(a) WS-345-20

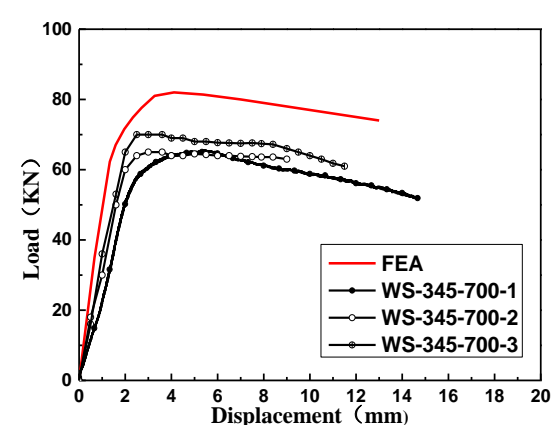

(d) WS-345-700

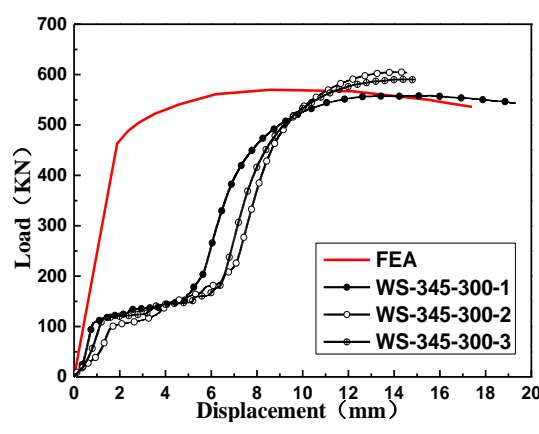

(b) WS-345-300

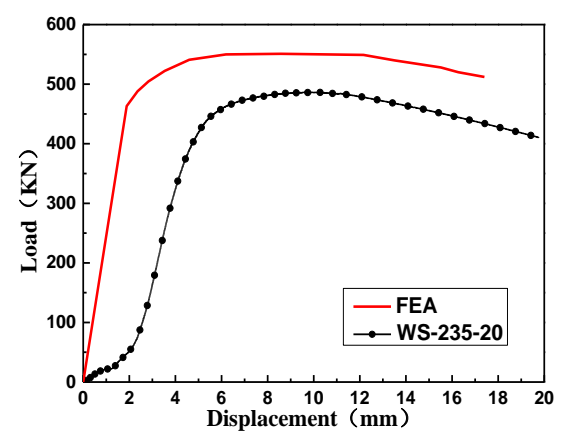

(e) WS-235-20

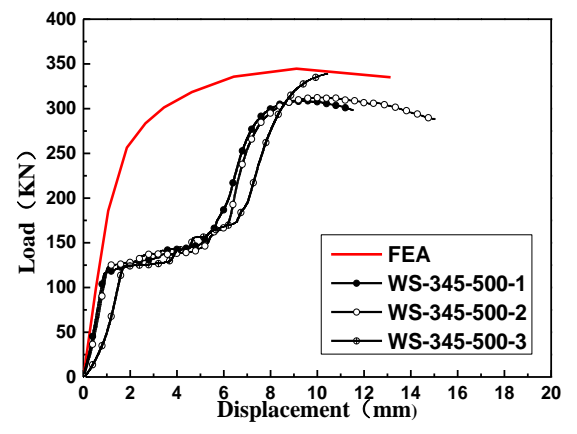

(c) WS-345-500

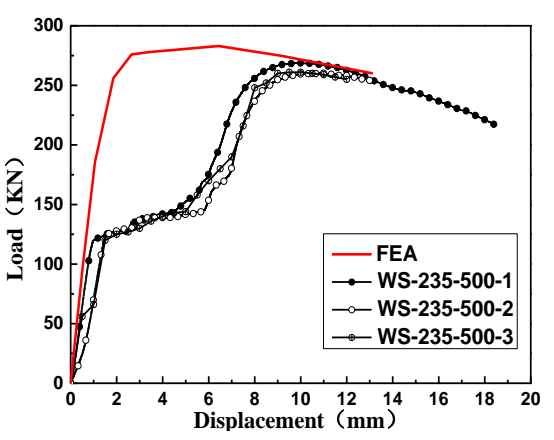

(f) WS-235-500

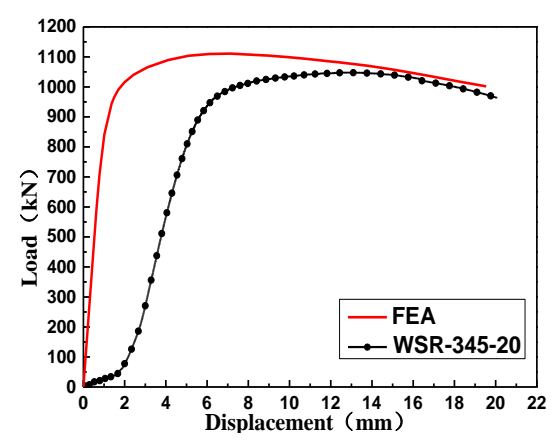

(g) WSR-345-20

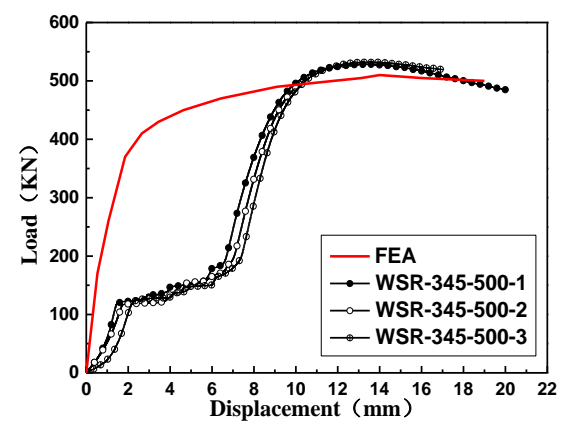

(h) WSR-345-500

Fig. 20 Comparison of load-displacement curves between simulation and test results

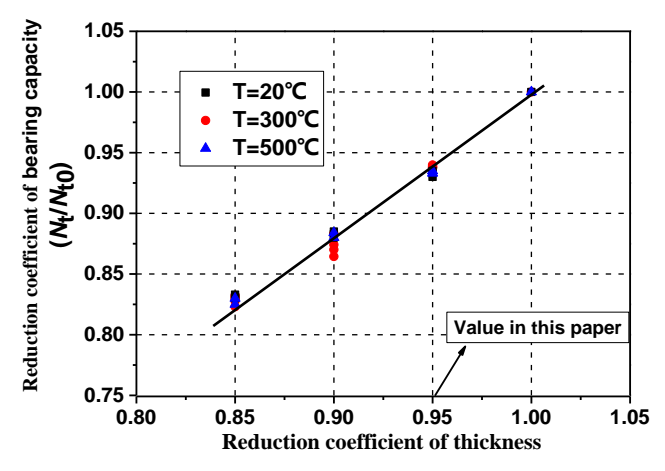

Fig. 21 The influence of reduction coefficient of thickness on bearing capacity

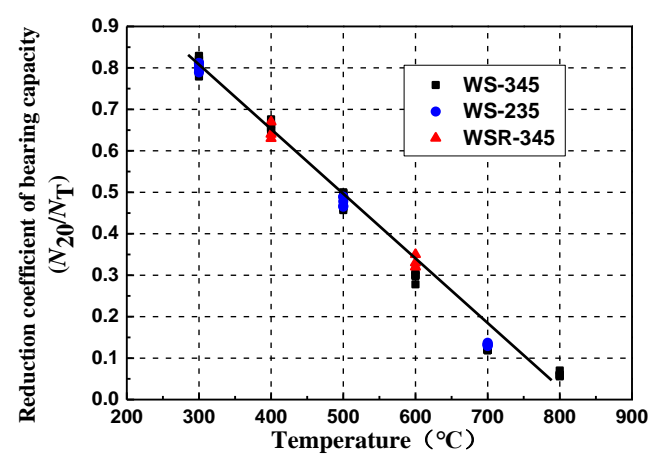

Fig. 22 The influence of temperature on bearing capacity 


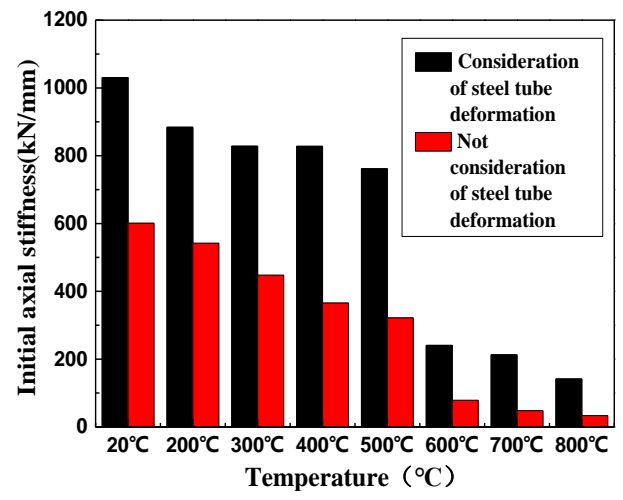

Fig. 23 Initial axial rigidity of the joint

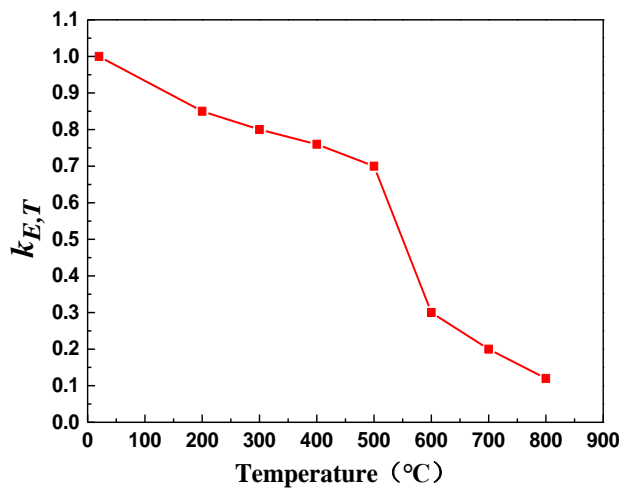

Fig. 24 Reduction coefficient of the initial axial rigidity

Table 5

Comparison of ultimate bearing capacity error

\begin{tabular}{|c|c|c|c|c|c|c|}
\hline Specimen No. & $N_{t}(\mathrm{kN})$ & $N_{f}(\mathrm{kN})$ & $\left(N_{f}-N_{t}\right) / N_{t}(\%)$ & $\eta_{t}$ & $\eta_{f}$ & $\left(\eta_{f}-\eta_{t}\right) / \eta_{t}(\%)$ \\
\hline WS-345-20 & 652.6 & 746.7 & 14.4 & 1 & 1 & -- \\
\hline WS-345-300 & 584.9 & 555.7 & -5.0 & 0.90 & 0.74 & -17.8 \\
\hline WS-345-500 & 320.4 & 348.5 & 8.8 & 0.49 & 0.47 & -4.0 \\
\hline WS-345-700 & 65.4 & 81.9 & 25.2 & 0.10 & 0.11 & -10.0 \\
\hline WS-235-20 & 486.7 & 574.3 & 18.0 & 1 & 1 & -- \\
\hline WS-235-500 & 252.7 & 283.6 & 12.2 & 0.52 & 0.49 & 5.8 \\
\hline WSR-345-20 & 1047.9 & 1110.9 & 6.0 & 1 & 1 & -- \\
\hline WSR-345-500 & 520.2 & 505.9 & -2.7 & 0.50 & 0.46 & -8.0 \\
\hline
\end{tabular}

Notes: $N_{t}$ is the tested bearing capacity. $N_{f}$ is the simulation bearing capacity. $\eta_{t}$ is the reduction coefficient of tested bearing capacity. $\eta_{f}$ is the reduction coefficient of simulated bearing capacity.

Table 6

Comparison of initial axial rigidity errors

\begin{tabular}{|c|c|c|c|c|c|c|}
\hline Specimen No. & $K_{t}$ & $K_{f}$ & $\left(K_{f}-K_{t}\right) / K_{t}(\%)$ & $k_{t}$ & $k_{f}$ & $\left(k_{f}-k_{t}\right) / k_{t} \quad(\%)$ \\
\hline WS-345-20 & 563 & 621 & 10.3 & 1 & 1 & -- \\
\hline WS-345-300 & 506 & 548 & 8.3 & 0.90 & 0.82 & -8.9 \\
\hline WS-345-500 & 391 & 442 & 13.0 & 0.69 & 0.71 & 2.9 \\
\hline WS-345-700 & 100 & 132 & 32 & 0.18 & 0.21 & 16.7 \\
\hline WS-235-20 & 386 & 445 & 15.3 & 1 & 1 & -- \\
\hline WS-235-500 & 269 & 329 & 18.2 & 0.70 & 0.74 & 5.7 \\
\hline WSR-345-20 & 656 & 693 & 5.6 & 1 & 1 & -- \\
\hline WSR-345-500 & 447 & 500 & 11.9 & 0.68 & 0.72 & 5.9 \\
\hline
\end{tabular}

Notes: $K_{t}$ is the tested rigidity. $K_{f}$ is the simulated rigidity. $k_{t}$ is the reduction coefficient of the tested rigidity. $k_{f}$ is the reduction coefficient of the simulated rigidity.

\subsection{Strain analysis}

The load-strain relation curve at different positions (1-6) of WS-345 at a high temperature is shown in Fig. 25. The results demonstrate that the steel tube (positions 1-6) of the specimens is maintained at the elasticity stage, which is attributed to the large thickness of the steel tube. The strain development of the spherical joint changes significantly with positions and temperature. In general, strain strength decreases dramatically along the radial direction of the spherical joint (from position 2 to position 4). Under a specific axial load, the maximum strain level is at the connection between the spherical joint and the steel tubes (positions 2 and 5). This phenomenon is consistent with the failure modes of the spherical joint in Fig. 7. For specimens at room temperature and at a low temperature $\left(<500{ }^{\circ} \mathrm{C}\right)$, only the connection between the spherical joint and the steel tubes enters the yield stage under a high load, whereas the remaining regions still maintain the elastic state. As temperature increases, the yield region expands. For example, positions 2, 3, and 4 of WS-345-700 reach the yield stage under a high load.

\section{Simplified calculation method}

In the Technical Regulation of Spatial Grid Structure (JGJ7-2010), the calculation formula of the compressive bearing capacity of the WHSJ at room temperature is:

$N_{U}=\left(0.32+0.6 \frac{d}{D}\right) \eta_{D} \pi t d f$ 


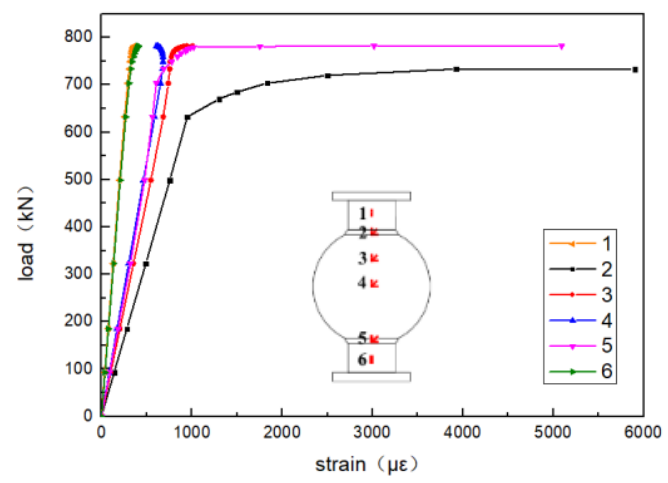

(a) WS-345-20

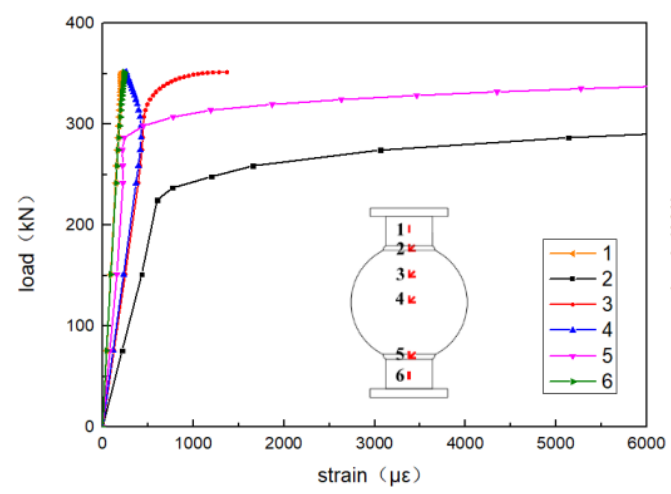

(c) WS-345-500

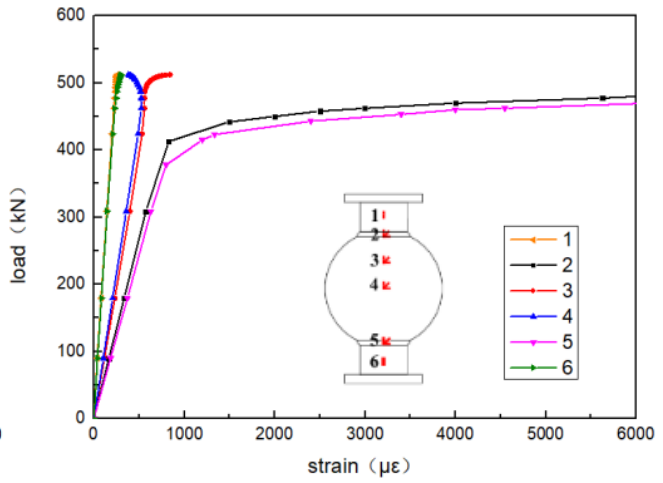

(b) WS-345-300

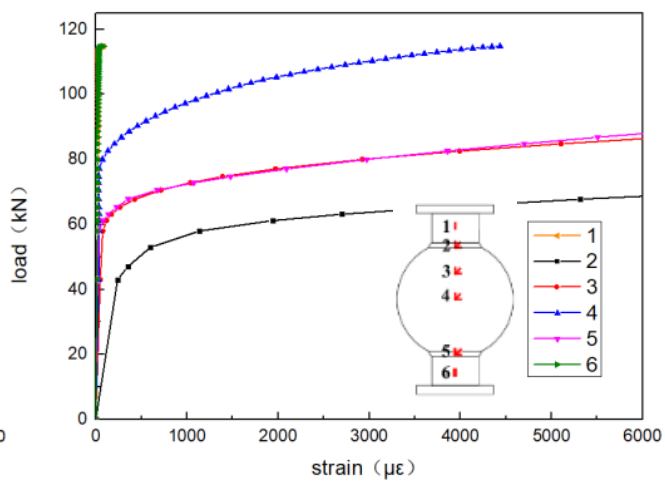

(d) WS-345-700

Fig. 25 Load-strain curves of WS-345

Table 7

Values of parameters

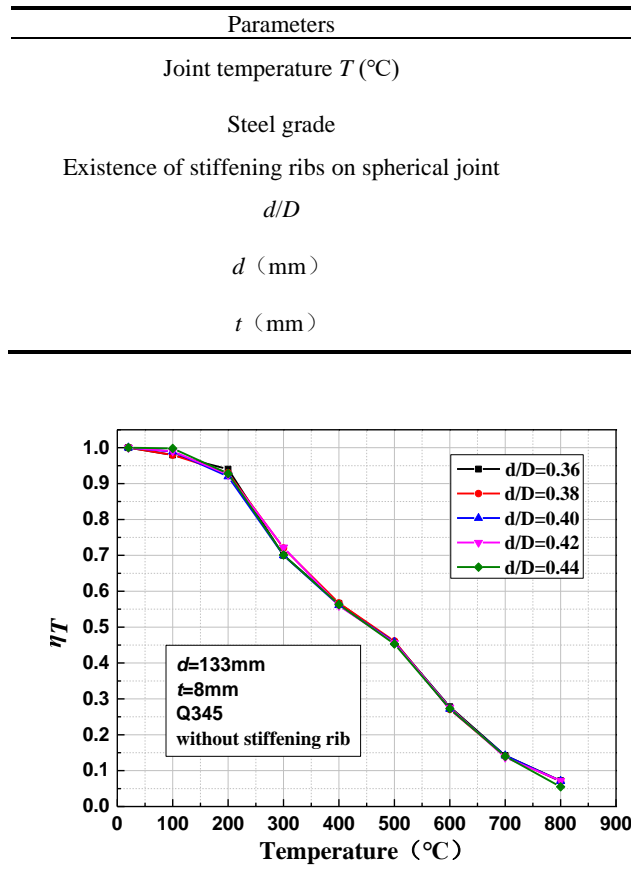

(a) $T\left({ }^{\circ} \mathrm{C}\right)$

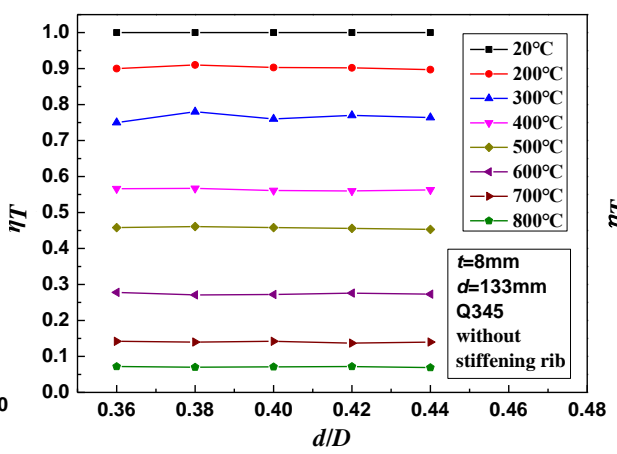

(b) $d / D$

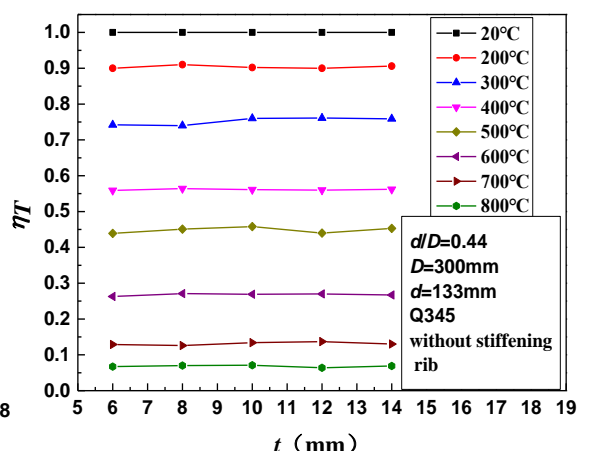

(c) $t(\mathrm{~mm})$
$6,8,10,12,14$
8 


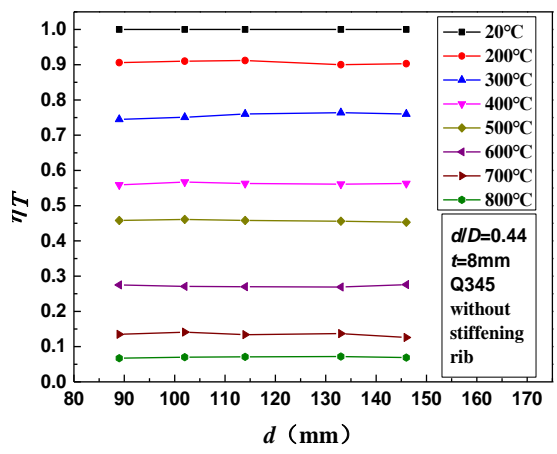

(d) $d(\mathrm{~mm})$

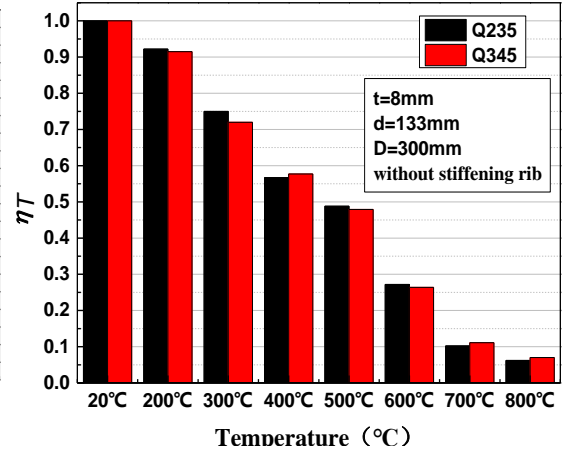

(e) Steel grade

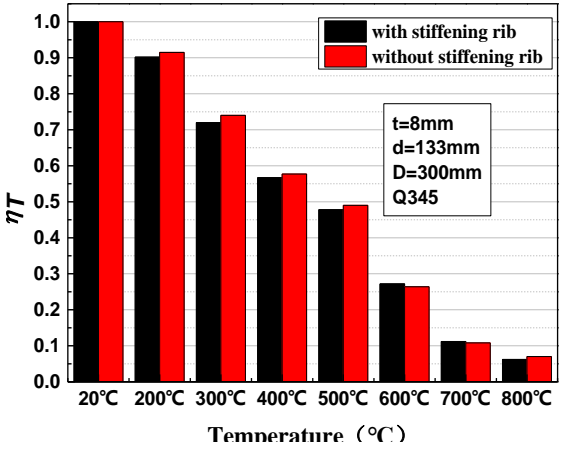

(f) With or without stiffening ribs

Fig. 26 Effects of key parameters on $\eta_{T}$

For the convenience of calculating the compressive bearing capacity of the WHSJ at a high temperature, a simplified calculation formula is proposed. In this formula, the concept of the reduction coefficient of the ultimate bearing capacity $\left(\eta_{T}\right)$ is introduced:

$$
N_{U T}=\eta_{T} N_{U}
$$

where $N_{U T}$ is the axial compressive bearing capacity of the WHSJ at a high temperature, and $N_{U}$ is the axial compressive bearing capacity of the WHSJ at room temperature and can be calculated according to Eq. (4).

The influences of key parameters on $\eta_{T}$ are studied on the basis of parameterization analysis results. Dimension parameters are designed in accordance with the Technical Regulation of Spatial Grid Structure (JGJ7-2010). All of the parameters are listed in Table 7, and their influences on $\eta_{T}$ are shown in Fig. 26. $\eta_{T}$ is mainly determined by $\mathrm{T}$ and slightly influenced by other factors. The relation curve between $\eta_{T}$ and $\mathrm{T}$ can be obtained from regression analysis (Fig. 27). The equation is shown as follows:

$\eta_{T}=\left\{\begin{array}{cc}1 & 20^{\circ} \mathrm{C}<T \leq 100^{\circ} \mathrm{C} \\ 1.04-4 \times 10^{-4} \mathrm{~T} & 100^{\circ} \mathrm{C}<\mathrm{T} \leq 200^{\circ} \mathrm{C} \\ 1.27-1.55 \times 10^{-3} \mathrm{~T} & 200^{\circ} \mathrm{C}<T \leq 800^{\circ} \mathrm{C}\end{array}\right.$

The axial compressive bearing capacity of the WHSJ, which is predicted in Eq. (5), is compared with the FEA results and the test results (Fig. 28(a) and (b)), thereby achieving high consistency. This result verifies the accuracy of the simplified calculation method.

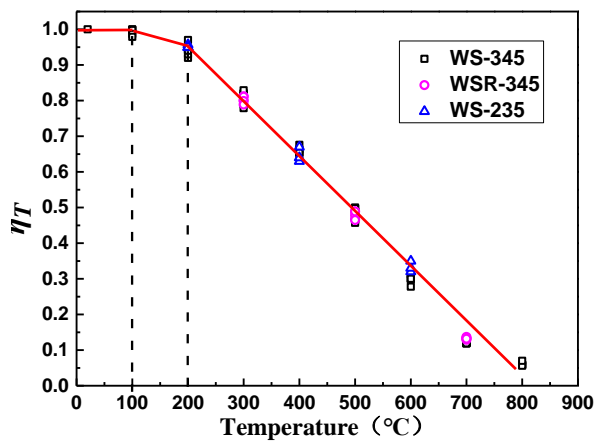

Fig. 27 The relation curve between $\eta_{T}$ and $T$

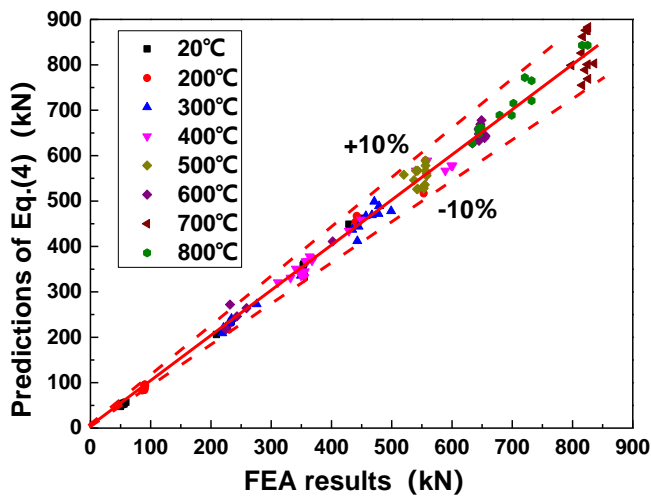

(a) Simplified calculation method and FEA results

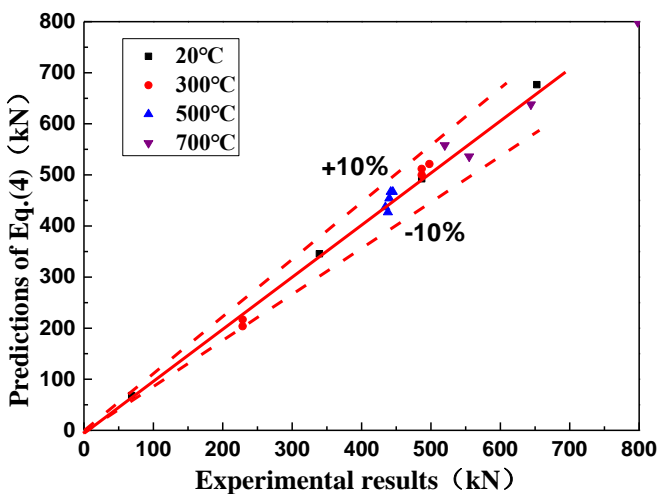

(b) Simplified calculation method and test results

Fig. 28 Verification of the simplified calculation method

\section{Conclusions}

WHSJs have been extensively applied to spatial grid structures. The study of the mechanical behavior of WHSJs at elevated temperatures provide important basis for assessing the fire damage of the whole structure. This paper presented experimental and numerical studies on the mechanical behavior of WHSJs at elevated temperatures. The failure mechanism and high-temperature attenuation pattern of the axial compression performance of WHSJs at elevated temperatures were explored via high-temperature axial compression experiments by using 18 specimens. A FE model was constructed and the reliability of this FE model was verified by experimental results. Simplified calculation methods, based on test results and parametric studies, were proposed to predict the load-bearing capacity of WHSJs at elevated temperatures. The findings of the simplified calculation method conformed to experimental results and numerical simulation results. Some major conclusions can be drawn:

The failure mode of the WHSJ at a high temperature is similar to that at room temperature. Bending invagination occurs at the connection between the spherical joint and the steel tubes, indicating plastic failure.

The ultimate load and the yield load of the WHSJ at $300{ }^{\circ} \mathrm{C}$ are $10 \%$ lower than those at room temperature. The ultimate load and the yield load of the WHSJ at $500{ }^{\circ} \mathrm{C}$ are about $50 \%$ lower than those at room temperature. At $700{ }^{\circ} \mathrm{C}$, 
they decrease by $90 \%$ compared with those at room temperature. The stiffening rib arrangement and the steel grade slightly influence the reduction coefficients of the yield load and the ultimate load of the WHSJ at a high temperature. The reduction coefficients of the ultimate load and the yield load of the spherical joint are consistent.

The initial axial rigidity of the WHSJ is significantly influenced by steel tube deformation that should be considered in calculating the initial axial rigidity of the joint. The initial axial rigidity of the WHSJ at $300{ }^{\circ} \mathrm{C}$ decreases by about $20 \%$ compared with those at room temperature and further decreases greatly after $500{ }^{\circ} \mathrm{C}$.

The tested results of bearing capacity, the reduction coefficient of bearing capacity, rigidity, and the reduction coefficient of rigidity are consistent with the simulation results. The errors between the test results and the simulation results are lower than $20 \%$ except those in some specimens.

Parameterized analysis indicates that the reduction coefficient of the bearing capacity of the WHSJ $\left(\eta_{T}\right)$ is mainly determined by test temperature. However, $\eta_{T}$ is less sensitive to other factors. The simplified calculation method based on abundant FEA results can reasonably predict the axial compressive bearing capacity of the WHSJ at high temperatures.

\section{Acknowledgments}

This study was financially supported by the National Natural Science Foundation of China (Grant No. 51678404).

\section{References}

[1] Fan F., Ma H.H. and Chen G.B., "Experimental study of semi-rigid joint systems subjected to bending with and without axial force", Journal of Constructional Steel Research, 68(1), 126-137, 2012

[2] Xu S., Chen Z.H. and Wang X.D., "Hysteretic out-of-plane behavior of the Temcor joint", Thin-Walled Structures, 94, 585-592, 2015.

[3] Gao F., Shao Y.B. and Gho W.M., "Stress and Strain Concentration Factors of Completely Overlapped Tubular Joints Under Lap Brace IPB Load", Journal of Constructional Steel Research, 63(3), 305-316, 2007

[4] Du W.F., Sun Y. and Yang M.J., "Bearing capacity of the cast-steel joint with branches under eccentric load", Journal of Constructional Steel Research, 135, 285-291, 2017.

[5] Han Q.H., Liu Y.M. and Zhang J.Y., "Mechanical behaviors of the Assembled Hub (AH) joints subjected to bending moment", Journal of Constructional Steel Research, 138, 806822,2017

[6] Liu X.L, "Design and Construction of Plate Grid Structures", Press of Tianjin University,
Tianjin, China, 2000

[7] Hou X.M., Zheng W.Z. and Kodul V., "Effect of temperature on mechanical properties of prestressing bars", Construction and Building Materials, 61, 24-32, 2014.

[8] Xue W.L. and Zhang Q.L., "Destructive mechanism and experimental study of welded hollow spherical joints connected with circular steel tubes”, Journal of Building Structures, 30(5), 155-161, 2009

[9] Ding Y., Qi L. and Li Z.X., "Mechanical calculation model for welded hollow spherical joint in spatial latticed structures", Advanced Steel Construction, 7(4), 330-343, 2011.

[10] Han Q.H. and Liu X.L., "Ultimate Bearing Capacity of the Welded Hollow Spherical Joints in Spatial Reticulated Structures", Engineering Structures, 26(1), 73-82, 2004.

[11] Li X., "Load-carrying Capacity and Practical Design Method of Welded Hollow Spherical Joints in Space Latticed Structures", Advanced Steel Construction, 6(4), 976-1000, 2010.

[12] Liu H.B., Ying J.J. and Chen Z.H., "Ultimate tensile and compressive performances of welded hollow spherical joints with H-beam", Journal of Constructional Steel Research, 150, 195 208, 2018.

[13] Han Q.H., Liu Y.M. and Xu Y., "Stiffness Characteristics of Joints and Influence on the Stability of Single-Layer Latticed Domes", Thin-Walled Structures, 107, 514-25, 2016.

[14] Zhao Z.W., Liu H.Q. and Liang B., "Influence of welded hollow spherical joints on the mechanical behavior of single-layer reticulated shell structures", Journal of the Brazilian Society of Mechanical Sciences and Engineering, 40,386, 2018.

[15] Zhao Z.W., Zhu H. and Chen Z.H., "Mechanical behavior of single-layer reticulated shell connected by welded hollow spherical joints with considering welding residual stress", Welding in the World, 60(1), 61-69, 2016.

[16] Wang P.P., Lei H.G. and Wang F., "Numerical Simulation Analysis of Residual Stress in Welded Hollow Spherical Joint with Circular Steel Tubes", Architectural Engineering and New Materials, 308-314, 2015.

[17] Zhao Z.W., Liu H.Q. and Liu B. "Assessment of the bending capacity of welded hollow spherical joints with pit corrosion", Thin-Walled Structures, 131, 274-285, 2018.

[18] Zhao Z.W., Liu H.Q. and Liu B., "Bending capacity of corroded welded hollow spherical joints", Thin-Walled Structures, 127, 523-539, 2018.

[19] JGJ 7-2010, Technical Specification for Space Frame Structures, Ministry of Construction of the People's Republic of China, Beijing, 2010.

[20] Lu J., Liu H.B. and Chen, Z.H., "Post-fire Behavior of Welded Hollow Spherical Joints Subjected to Eccentric Loads", International Journal of Steel Structures, 18(2), 456-472, 2018.

[21] Liu H.B., Lu J. and Chen Z.H., "Residual behavior of welded hollow spherical joints after exposure to elevated temperatures", Journal of Constructional Steel Research, 137, 102-118, 2017.

[22] Lu J., Liu H.B. and Chen Z.H., "Behavior of Welded Hollow Spherical Joints After Exposure to ISO-834 Standard Fire", Journal of Constructional Steel Research, 140, 108-124, 2018

[23] Xue S.D. and Qiu L., "Experimental investigation on compression performance of welded hollow spherical joints in fire", Journal of Building Structures, 32(2), 113-119, 2011.

[24] Eurocode3: Design of steel structures. Part1-2: General rules -Structural fire design. Brussels, Belgium, European Committee for Standardization, 2005.

[25] Liu X.L. and Chen Z.H., "Failure Mechanism Analysis and Bearing Capacity Test Study of Grid Welded Hollow Spherical Joints", Journal of Building Structures, 3, 38-44, 1994.

[26] Chen Z.H. and Liu X.L., "Study on Calculation Formula of Bearing Capacity of Welded Hollow Spherical Joints", Proceedings of the 11th Academic Conference on Space Structure, 2005 